\title{
Right ventricle anatomy can predict new onset ventricular tachycardia in patients with repaired tetralogy of Fallot
}

\author{
Beatrice Bonello ${ }^{2,1^{*}}$, Aleksander Kempny ${ }^{3}$, Anselm Uebing ${ }^{3}$, Wei Li ${ }^{3}$, Philip J Kilner ${ }^{2}$, Gerhard Diller ${ }^{3}$, \\ Dudley Pennell ${ }^{2}$, Daryl Shore ${ }^{3}$, Sabine Ernst ${ }^{3}$, Michael Gatzoulis ${ }^{3}$, Sonya V Babu-Narayan ${ }^{2}$ \\ From 16th Annual SCMR Scientific Sessions \\ San Francisco, CA, USA. 31 January - 3 February 2013
}

\section{Background}

Repaired tetralogy of Fallot (rtoF) patients are at risk ventricular tachyarrhythmia and sudden cardiac death. Risk stratification for arrhythmia remains difficult.

We aimed to investigate whether cardiac anatomy and function assessed by cardiac magnetic resonance imaging (CMR) predict arrhythmia.

\section{Methods}

One-hundred-and-fifty-four adults with rtoF, median age 30.8 (21.9-40.2) years, were studied with a standardised protocol including cardiovascular magnetic resonance (CMR) and prospectively followed-up over median 5.6 (4.6-7.0) years for the pre-specified endpoints of newonset ventricular tachyarrhythmia (sustained ventricular tachycardia/ventricular fibrillation).

\section{Results}

Nine patients had ventricular tachyarrhythmia (6\%) during follow-up. Patients who developed ventricular tachyarrhythmia were older (42.5 [34.9-50.2] vs. 29 [21-40] years; $\mathrm{p}=0.01)$, had a later repair (12.8 [6.2-13.9] vs. 4.4 [2-8] years; $p=0.02)$, larger akinetic right ventricular outflow track (RVOT) region (Figure ) (length 55 [34-60] vs. 30 [20-40] mm; $\mathrm{p}=0.002$ ) and a lower RV ejection fraction (42 [40-52] vs. $53[51-55] \% ; p=0.01)$, compared to the other patients. On univariate Cox analysis, RVOT akinetic region length and RV ejection fraction were predictive of ventricular tachyarrhythmia. On stepwise Cox regression analysis, the RVOT akinetic region length was the only remaining predictor (Hazard ratio 1.05, 95\% Confidence

\footnotetext{
${ }^{2}$ CMR Department, Royal Brompton Hospital, London, UK

Full list of author information is available at the end of the article
}

Interval 1.01-1.08 per mm; $\mathrm{p}=0.004)$. The survival ROC curve analysis indicated a cut-off value of $30 \mathrm{~mm}$ as a predictor of VA during 6 year follow-up with an AUC of 0.77, sensitivity of $83 \%$ and specificity of $61 \%$. RVOT akinetic area length $>30 \mathrm{~mm}$ predicted reduced VA-free survival (Logrank $\mathrm{p}=0.002)$.

\section{Conclusions}

Conclusions: RVOT akinetic region length predicts ventricular arrhythmia in late follow-up of rtoF. This is simple,

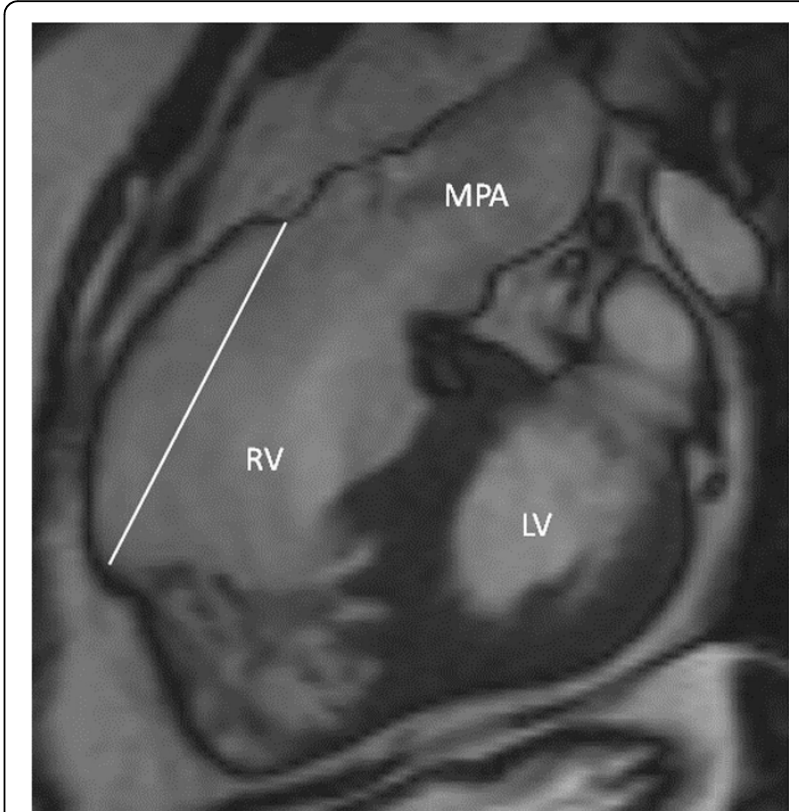

Figure 1 Cine steady state free precession right ventricular outflow track view showing a large akinetic area $(50 \mathrm{~mm})$. 
feasible measurements for inclusion in serial surveillance and risk stratification of rtoF patients.

\section{Funding}

British Heart Foundation Fellowship (SVB-N).

French Federation of Cardiology (BB).

Unrestricted Actelion educational grant (GD).

The study was supported by the NIHR Cardiovascular Biomedical Research Unit of Royal Brompton and Harefield NHS Foundation Trust and Imperial College London.

\section{Author details}

${ }^{1} \mathrm{CHU}$ Timone Marseille, Marseille, France. ${ }^{2} \mathrm{CMR}$ Department, Royal Brompton Hospital, London, UK. ${ }^{3}$ Congenital Heart Disease, Royal Brompton Hospital, London, UK.

Published: 30 January 2013

doi:10.1186/1532-429X-15-S1-0100

Cite this article as: Bonello et al:: Right ventricle anatomy can predict new onset ventricular tachycardia in patients with repaired tetralogy of Fallot. Journal of Cardiovascular Magnetic Resonance 2013 15(Suppl 1): 0100 .

Submit your next manuscript to BioMed Central and take full advantage of:

- Convenient online submission

- Thorough peer review

- No space constraints or color figure charges

- Immediate publication on acceptance

- Inclusion in PubMed, CAS, Scopus and Google Scholar

- Research which is freely available for redistribution

Submit your manuscript at www.biomedcentral.com/submit 